\title{
Downregulation of Angiogenesis Factors, VEGF and PDGF, after Rapid IgE Desensitization and Oral Immunotherapy in Children with Food Allergy
}

\author{
Paloma Poza-Guedes, ${ }^{1}$ Yvelise Barrios, ${ }^{2}$ Victoria Fuentes, ${ }^{3}$ Andres Franco, ${ }^{2}$ \\ Inmaculada Sánchez-Machín, ${ }^{1}$ Elena Alonso, ${ }^{3}$ Ruperto González Pérez, ${ }^{1}$ Sonsoles Infante, ${ }^{3}$ \\ Lydia Zapatero, ${ }^{3}$ and Víctor Matheu ${ }^{1,4}$ \\ ${ }^{1}$ Consulta de Alergia Infantil, Unidad de Alergología-Norte, Hospital del Tórax/Ofra, CHUNSC, Ofra, Spain \\ ${ }^{2}$ Immunology, Hospital Universitario de Canarias, La Laguna, Spain \\ ${ }^{3}$ Consulta de Alergia Infantil, Hospital Infantil Gregorio Marañon, Madrid, Spain \\ ${ }^{4}$ Department of Clinical Sciences-Division IV, Lund University, Sweden
}

Correspondence should be addressed to Víctor Matheu; victor.matheu@med.lu.se

Received 16 February 2014; Revised 6 April 2014; Accepted 29 April 2014; Published 3 June 2014

Academic Editor: Brian Oliver

Copyright (c) 2014 Paloma Poza-Guedes et al. This is an open access article distributed under the Creative Commons Attribution License, which permits unrestricted use, distribution, and reproduction in any medium, provided the original work is properly cited.

Background. Angiogenesis has a key role in several conditions and is regulated by several factors such as the platelet-derived growth factor (PDGF) or the vascular endothelial growth factor (VEGF). The goal of this study was to investigate the possible role of PDGF and VEGF in a group of patients with severe food allergy. Methods. We design a prospective longitudinal study $(n=30)$ with patients with persistent cow's milk proteins (CMP) allergy. After achieving a CMP rush desensitization protocol, a clinical followup including SPT and blood samples to determine sIgE, protein levels, PDGF, and VEGF-A and a panel of the most representative $\mathrm{Th}_{1}, \mathrm{Th}_{2}, \mathrm{~T}_{\text {reg }}$, and $\mathrm{Th}_{17}$ cytokines were also monitored. Results. Baseline levels of PDGF and VEGF in the CMP allergic patients $(1170 \mathrm{pg} / \mathrm{mL}$ and $253 \mathrm{pg} / \mathrm{mL})$ were different compared to those nonallergic CMP control subjects $(501 \mathrm{pg} / \mathrm{mL}$ and $108 \mathrm{pg} / \mathrm{mL})$. Both PDGF and VEGF were significantly downregulated $(P<0.05) 6$ months after completion of the CMP desensitization process and remained significantly decreased 12 months later. Conclusion. The present study shows a significant increase of PDGF and VEGF in anaphylaxis suffering children compared to a control group. Interestingly, both VEGF and PDGF were significantly downregulated after completing a full CMP rush IgE desensitization.

\section{Introduction}

Food allergy is a growing problem in developed countries and a recent meta-analysis in US patients found an increase of almost $20 \%$ in the current prevalence of food allergy over the past decade [1]. Although food allergy patients are generally expected to outgrow their condition, it may take longer than previously believed [2]. Regrettably, despite strict dietary avoidance, food allergy still continues to be the leading cause of anaphylaxis [3] among the pediatric patients with a profound impairment in their quality of life [4]. These are only some of the encouraging reasons that lead an increasing number of investigators to develop novel therapeutic approaches (i.e., food desensitization and/or food immunotherapy) to a better management of this health condition.

Angiogenesis, the blood vessel formation from alreadyexisting blood vessel tissue, is regulated by several factors which have received an increasing interest because of their role in tumor growth and metastatic spread. One of the factors, the platelet-derived growth factor (PDGF), has been linked to several diseases such as malignant diseases and atherosclerosis or fibrosis [5]. PDGF is synthesized and released by platelets upon activation and smooth muscle or endothelial cells. PDGF can also be released by activated 
macrophages [6]. A different angiogenic factor, the vascular endothelial growth factor (VEGF), is described as the most potent proangiogenic factor regulating endothelial cells, increasing vascular permeability, promoting cell migration, and inhibiting apoptosis [7]. VEGF has been identified as an important target of cancer therapy [8]. The block of endothelial cell VEGF activity inhibits tumor angiogenesis, normalizes tumor vasculature, facilitates improved chemotherapy delivery, and prevents the recruitment of progenitor cells from the bone marrow [8].

However, vascular remodeling is associated with increased vascular permeability; it is also a key feature in the pathogenesis of many chronic inflammatory diseases [9] including lung disorders [10] such asthma [11, 12]. It has been also shown to have an essential role of nitric oxide in VEGFinduced, asthma-like angiogenic, physiologic responses in the lung and some features of phenotype as mucus [10], and it is even linked with atopic dermatitis [13]. In addition, in vitro studies have also proved that $\operatorname{IgE}$ could induce the VEGF production in mast cell lines [14].

The goal of this study was to investigate the role of a panel of the most representative cytokines of the $\mathrm{Th}_{1}, \mathrm{Th}_{2}, \mathrm{~T}_{\text {reg }}$, and $\mathrm{Th}_{17}$ and the angiogenic factors PDGF and VEGF in a group of patients with severe allergy - that is, anaphylaxis - after the ingestion of cow's milk protein (CMP), the most prevalent food allergy in the early years of life. In addition, we have monitored the variation in these factors before and after the fulfillment of a standardized clinical intervention (i.e., CMP rush desensitization) with a marked clinical outcome in the course of the persistent disease.

\section{Methods}

2.1. Study Design and Population. We design a prospective longitudinal series study of 30 pediatric patients with a diagnosis of persistent cow's milk proteins (CMP) severe allergy. All children included in the active study group complained with anaphylaxis episodes [15] after the ingestion of CMP and frequent nonscheduled visits to the Emergency Room (ER), despite a correct CMP restrictive diet. These patients have positive skin prick tests and high levels of specific $\operatorname{IgE}(\operatorname{sgE})$ antibodies to CMP, with a distinct immunological phenotype showing low levels of the granule neutral proteases such as monocyte chemotactic protein 1 (MCP-1) and macrophage inflammatory protein $1 \alpha$ (MIP- $1 \alpha)$, as previous described $[15,16]$. A matched group of 30 pediatric patients with no food allergy and no dietary restrictions fulfilled the control group. The informed consent was obtained from parents or guardians and the CMP protocol has been previously approved by the Hospital Ethics Committee (PI CHUNSC: $35 / 11)$.

2.2. Clinical Intervention. Those patients with CMP anaphylaxis underwent a two-step standardized protocol starting with a rapid CMP desensitization at the Pediatric Critical Care Unit and followed by a subsequent oral CMP immunotherapy treatment (OIT) at the Allergy Office to achieve tolerance to the CMP contained in a glass of milk $(250 \mathrm{~mL})$ in 6 weeks as described elsewhere [15]. Allergic patients and their tutors were trained and fostered to recognize and treat the early symptoms of allergic reactions (oral antihistamines or corticosteroids), including anaphylaxis [17] with epinephrine autoinjector device, while kept in permanent telephone contact with the ER medical staff.

\subsection{Serum Sample Collection and Measurement of Protein} and Factors. A clinical followup including sIgE and blood samples for the measurement of protein levels was collected and monitored at different timelines (baseline and 6 and 12 months) for every patient. After venopuncture, serum was obtained after centrifugation and stored at $-80 \mathrm{C}$ until the assay experiment was completed. All in vitro experiments were done at the same assay to avoid any in-house differences. Specific IgE antibodies against CMP, casein, $\alpha$-lactalbumin, and $\beta$-lactoglobulin were determined by using enzimoimmunoassay (Phadia, Uppsala, Sweden). Along with PDGF and VEGF-A, a panel of the most representative cytokines of the $\mathrm{Th}_{1}, \mathrm{Th}_{2}, \mathrm{~T}_{\text {reg }}$, and $\mathrm{Th}_{17}$ response was determined in plates by using a designed immunoassay analysis. Very briefly, the wells in the plate were soaked and a diluted capture bead solution was added. Then it was vortex and sonicated. Then, after washes, an incubation buffer was added to every well and standards were added into designated wells. Samples were added with assay diluents. The plate was then covered and incubated for 2 hours at room temperature on a shaker. Then, after washes, the prepared biotinylated detector antibody diluting in biotin diluents was added to every well. The plate was covered and incubated for 1 hour on a shaker. After new washes, diluted Streptavidin-RPE was added to each assay well. Plate was covered and incubated for 30 minutes on a shaker. Finally, after washing, standards were added into wells and plate was covered and incubated the plate for 2 hours at room temperature on a shaker. The plate was read on any immunofluorescence reader.

2.4. Statistical Analysis. Statistical analysis was performed by application of Mann-Whitney $U$ test using StatView software. The differences were considered significant when $P$ was equal or less than $0.05 P<0.05$.

\section{Results}

The active study group included 30 children (24:6 male: female ratio; $2-15$ y.o.: median 7 y.o.) with a clinical diagnosis of persistent CMP allergy expressed as severe recurrent grade II/III anaphylactic episodes [15]. The diagnostic workout showed positive skin prick tests and very high levels of sIgE antibodies to whole CMP (average sIgE to CMP $189 \mathrm{kU} / \mathrm{l}$ ) and casein protein (178 kU/l) (Table 1). Significant low levels of two macrophage (MIP-1alpha) and monocyte proteins (MCP-1) [15] compared to control group were also observed. MIP levels were $11.4 \mathrm{pg} / \mathrm{mL}$ in the active group compared to $26.9 \mathrm{pg} / \mathrm{mL}$ in control group $(P<0.05)$; MCP levels was $11.9 \mathrm{pg} / \mathrm{mL}$ in the active group compared to $28.7 \mathrm{pg} / \mathrm{mL}$ in control group $(P<0.05)$.

All patients successfully completed the clinical follow-up during 12 months with a daily dose of $250 \mathrm{~mL}$ of cow's milk. 
TABLE 1: Figures of levels of specific IgE against some cow's milk protein fractions in the patient group and control group.

\begin{tabular}{|c|c|c|c|c|}
\hline \multirow{3}{*}{ Allergen } & \multicolumn{3}{|c|}{ Patients group $n=30$} & $\begin{array}{c}\text { Control group } \\
n=30\end{array}$ \\
\hline & \multicolumn{4}{|c|}{ Specific IgE (kU/L) } \\
\hline & Average & Range & Median & \\
\hline Whole cow's Milk & 189 & $30-586$ & 146 & $<0.35$ \\
\hline Casein & 178 & $26-544$ & 90 & $<0.35$ \\
\hline$\alpha$-lactalbumin & 21 & $9-34$ & 21 & $<0.35$ \\
\hline$\beta$-lactoglobulin & 16 & $2-38$ & 7 & $<0.35$ \\
\hline
\end{tabular}

A significant decrease in the degree of the sensitization was observed by either in vivo (SPT) or in vitro (sIgE) tests or both (Table 1). Most of the CMP adverse reactions were recorded during the first 18 weeks of the protocol. Nonscheduled assistance in the ER was needed in only two patients while the rest of the recorded CMP adverse reactions were properly managed and treated by patients, parents, or guardians at home.

Baseline levels (i.e., prior to CMP desensitization) of PDGF in patients were different compared to the nonallergic children $(1170 \mathrm{pg} / \mathrm{mL}$ and $501 \mathrm{pg} / \mathrm{mL}$, resp.). The basal levels of VEGF were also significantly different in both groups $(253 \mathrm{pg} / \mathrm{mL}$ and $108 \mathrm{pg} / \mathrm{mL})$. In both cases, the differences were statistically significant with a $P<0.05$.

Followup of the levels of both PDGF and VEFG factors were determined and were significantly downregulated $(P<$ 0.05) 6 and 12 months after fulfilling the CMP desensitization protocol (Figure 1).

There were not any significant differences in the basal levels of some $\mathrm{Th}_{2}$ cytokines between the active and the control group. IL-4 levels were $22.3 \mathrm{pg} / \mathrm{mL}$ in active group and $31.5 \mathrm{pg} / \mathrm{mL}$ in control group, IL-5 levels were $12.7 \mathrm{pg} / \mathrm{mL}$ in active group versus $15 \mathrm{pg} / \mathrm{mL}$ in control group, IL-6 levels were $6.9 \mathrm{pg} / \mathrm{mL}$ in active group versus $3.0 \mathrm{pg} / \mathrm{mL}$ in control group, IL-8 levels were $21.6 \mathrm{pg} / \mathrm{mL}$ in active group versus $21.1 \mathrm{pg} / \mathrm{mL}$ in control group, and IL-13 levels were $8.2 \mathrm{pg} / \mathrm{mL}$ in active group versus $7.0 \mathrm{pg} / \mathrm{mL}$ in control group.

No significant differences were either observed in other cytokines tested in both groups (active and control group at baseline time such as IL-2 $(20.0 \mathrm{pg} / \mathrm{mL}$ in active group versus $17.5 \mathrm{pg} / \mathrm{mL}$ in control group), IL-12p40 (381 pg/mL in active group versus $305.5 \mathrm{pg} / \mathrm{mL}$ in control group), IL-12p70 $(19.2 \mathrm{pg} / \mathrm{mL}$ in active group versus $25.0 \mathrm{pg} / \mathrm{mL}$ in control group), IFN- $\gamma(22.3 \mathrm{pg} / \mathrm{mL}$ in active group versus $31.5 \mathrm{pg} / \mathrm{mL}$ in control group) and TNF- $\alpha$ (17.8 pg/mL in active group versus $14.7 \mathrm{pg} / \mathrm{mL}$ in control group), TGF- $\beta(3.9 \mathrm{pg} / \mathrm{mL}$ in active group versus $3.5 \mathrm{pg} / \mathrm{mL}$ in control group), IL-10 $(8.7 \mathrm{pg} / \mathrm{mL}$ in active group versus $9.0 \mathrm{pg} / \mathrm{mL}$ in control group), and IL17 $(12.5 \mathrm{pg} / \mathrm{mL}$ in active group versus $13.0 \mathrm{pg} / \mathrm{mL}$ in control group).

As shown in Figure 2, no significant differences were found in IL-4, IL-5, IL-6, IL-8, or IL-13 levels between the basal and 12 months after treatment in the active group. However, differences between basal time and 12 months in active group were near to be significant with $P<0.1$ with a trend in the case of IL-5 $(P=0.06)$, IL-6 $(P=0.09)$, and eotaxin $(P=0.07)$ (Figure 2 ).

Similarly, no significant differences were observed in IL-2, IL-12p40, IL-12p70, IFN- $\gamma$ and TNF- $\alpha$, TGF- $\beta$, IL-10, and IL17 (Figure 3). However, again a tendency to observe a significant difference was observed in IL-12p40 $(P=0.08)$ and IL-10 levels $(P=0.09)$.

Finally, the basal levels of MCP-1 $(11.1 \mathrm{pg} / \mathrm{ml})$ and MIP$1 \alpha(12.1 \mathrm{pg} / \mathrm{ml})$ in children with anaphylaxis were significantly lower than children of the control group (MCP-1 $28.4 \mathrm{pg} / \mathrm{mL}$; and MIP- $1 \alpha, 29.8 \mathrm{pg} / \mathrm{mL}$ ). Levels of these downregulated MCP and MIP-1 $\alpha$ did not significantly changed one year after oral immunotherapy as previously observed [15].

Remarkably, in all cases, It must be noted that all assays of each of the cytokines were performed under the same conditions and the same plate at the same time, to avoid differences between assays.

\section{Discussion}

Anaphylaxis is known as the most severe allergic reaction [3]. Insect sting, drugs, foods, and even mites are able to trigger human anaphylaxis after activating specific receptors on the mast cell surface. IgE- and non-IgE-dependent mechanisms may cause degranulation of mast cells releasing preformed mediators such as histamine, proteoglycans, or serine proteases and also cytokines and de novo lipid mediators.

In early 70 s a platelet-activating factor was first linked with allergy and IgE response [18]. This factor, so-called PAF, has been recently defined as an important mediator playing a pivotal role that correlates with the severity of anaphylaxis [19, 20]. In fact, the key treatment of anaphylaxis, epinephrine, has also been associated with human smooth muscle cells after stimulation with PAF [21].

In this study, we were looking for different platelet associated factors, such as PDGF since it can not only be synthesized by activated platelets but also be released by activated macrophages [6]. Interestingly, we have found a significant increase of PDGF levels in the CMP anaphylactic children compared to the CMP nonallergic control subjects. Furthermore, those levels of PDGF were later significantly downregulated after the implementation of a specific clinical intervention as a rapid CMP desensitization protocol, while no changes were found within the control children. This group of CMP anaphylactic patients also presents high levels of VEGF, another potent proangiogenic factor that specifically acts on endothelial cells increasing the vascular permeability. In fact, some early findings provided the evidence that human peripheral blood eosinophils induce angiogenesis [22], the growth of new vessels from preexisting ones, and to some extent VEGF could play an important role in angiogenesis, the subsequent airway remodeling in bronchial asthma [23] and the different phenotypes of asthma [10].

The CMP anaphylactic patients that underwent the twostep CMP rush desensitization had significantly lower levels of PDGF and VEGF-A 6 months after completing the protocol compared to their own baseline determinations. In contrast, the serum levels of the $\mathrm{Th}_{1}, \mathrm{Th}_{2}, \mathrm{Th}_{17}$, and $\mathrm{T}_{\text {reg }}$ key 


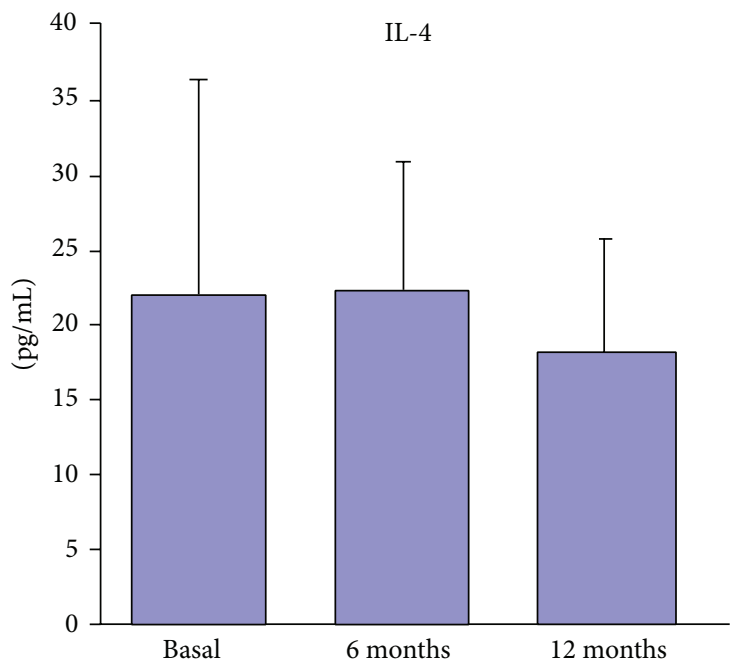

(a)

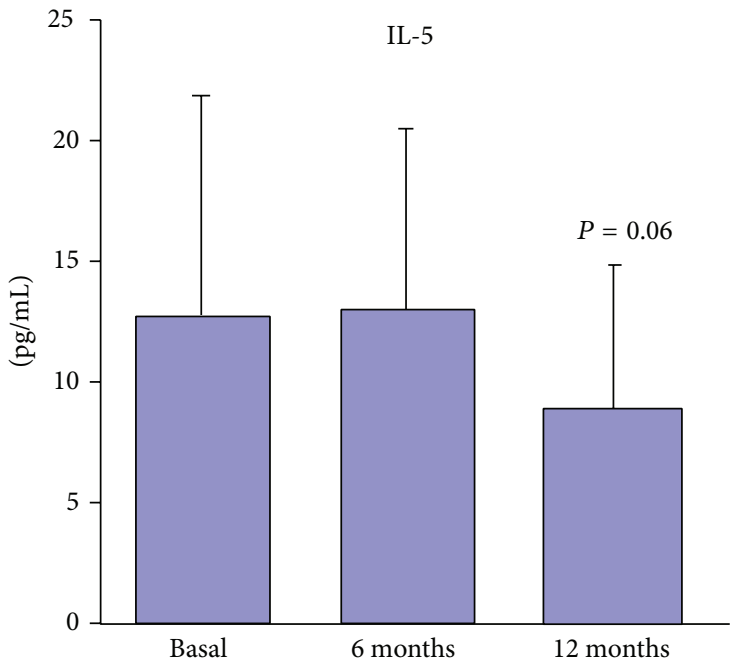

(c)

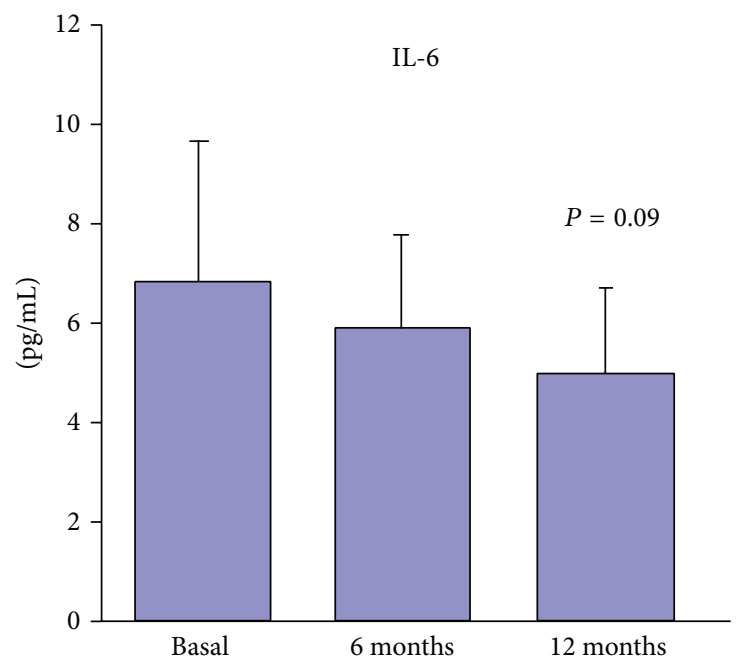

(e)

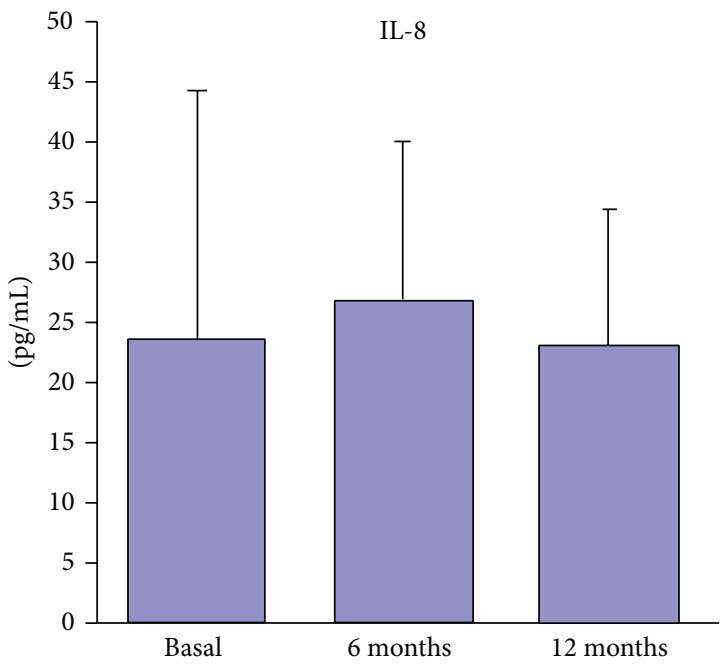

(b)

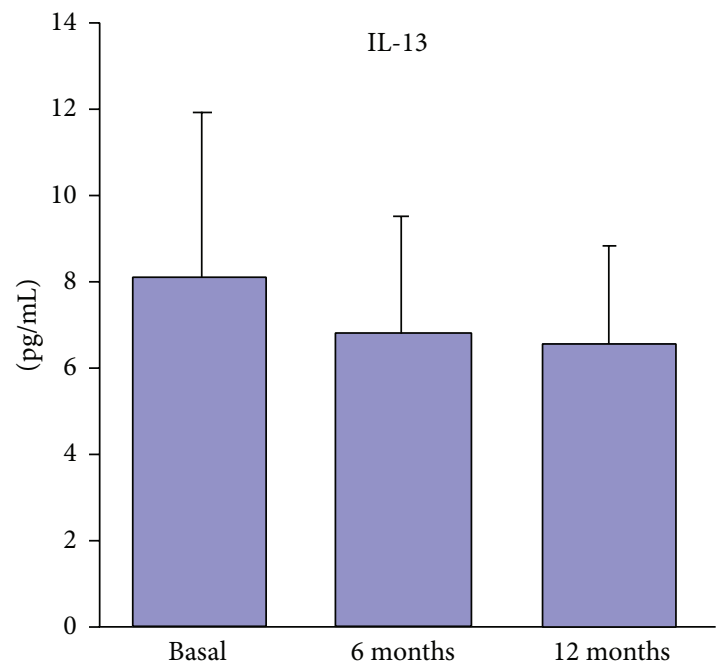

(d)

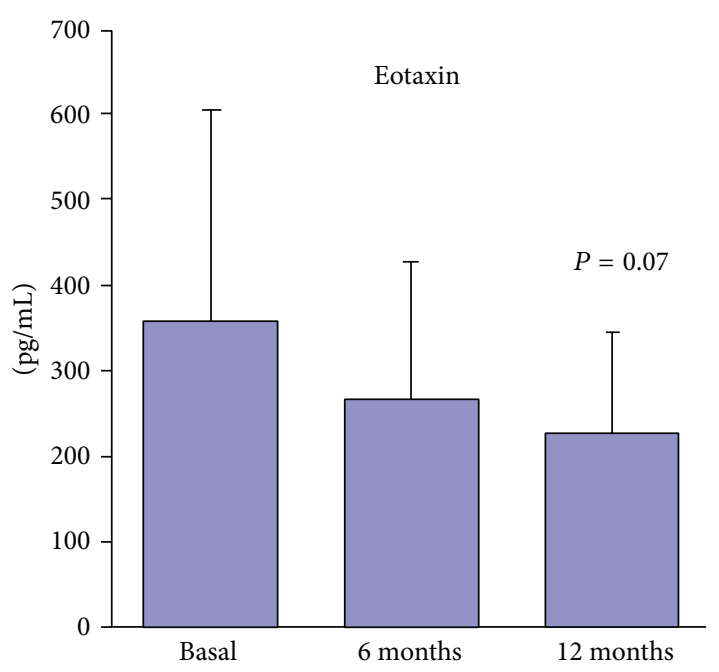

(f)

FIGURE 1: Levels of $\mathrm{Th}_{2}$ cytokines in the active group (mean and standard error of patients $-n=30$-at basal time and 6 and 12 months). In control group there were no differences at any time. 


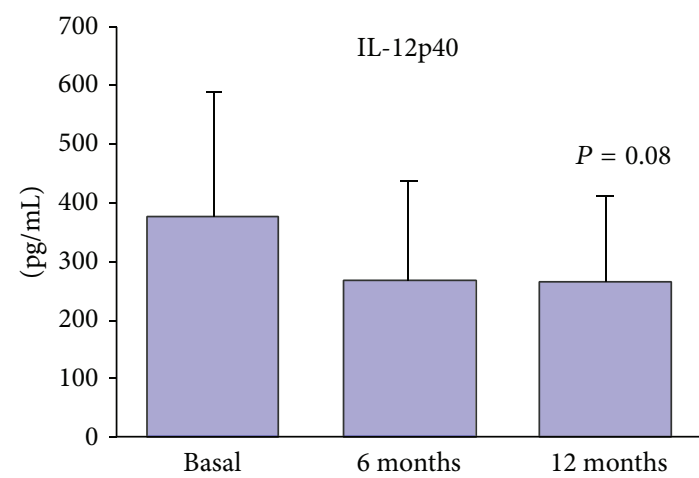

(a)

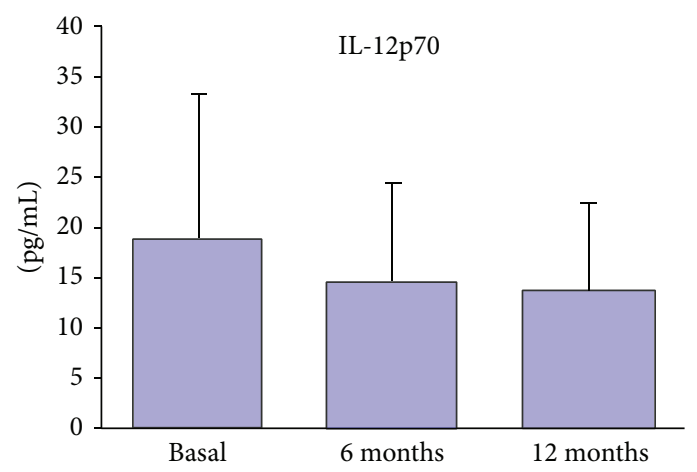

(c)

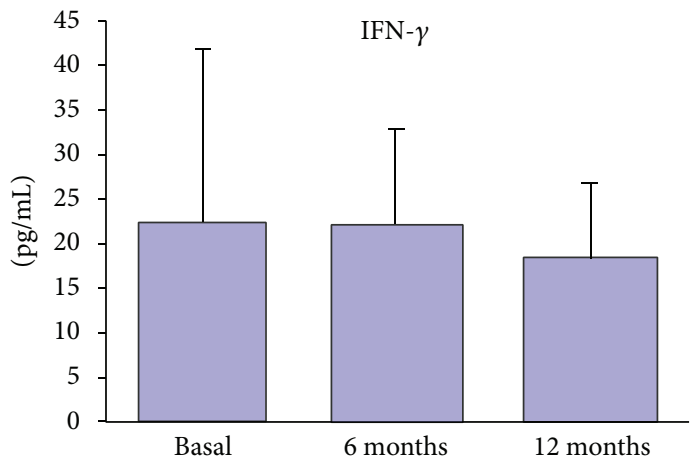

(e)

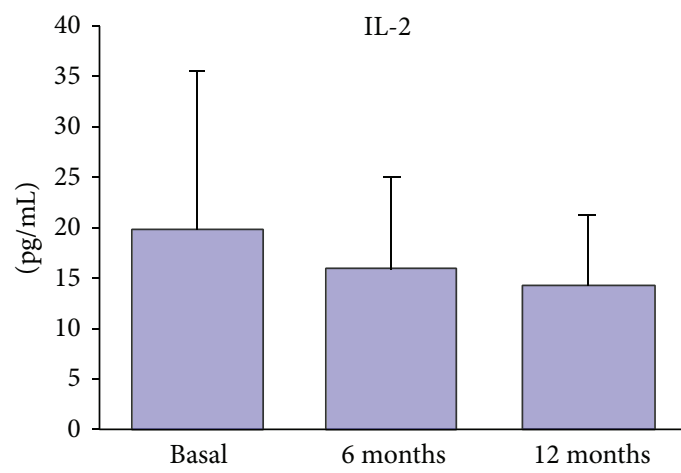

(g)

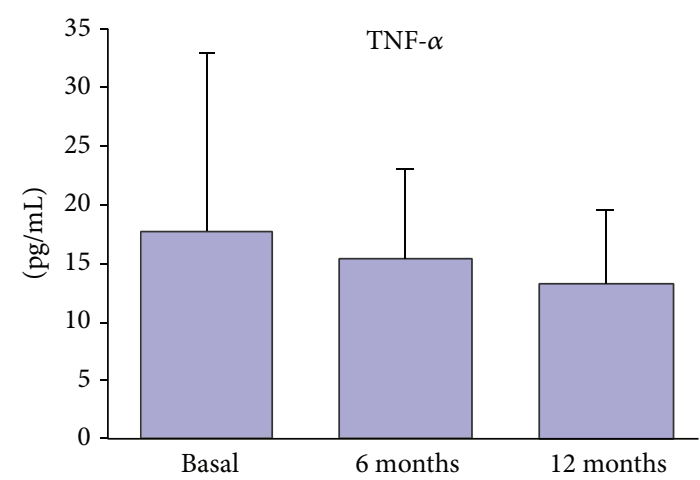

(b)

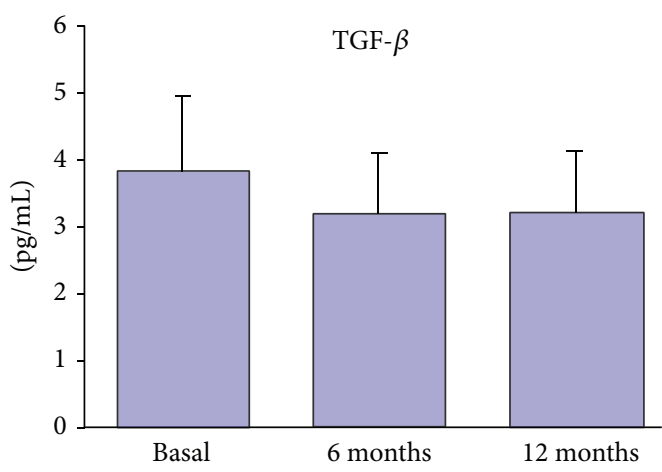

(d)

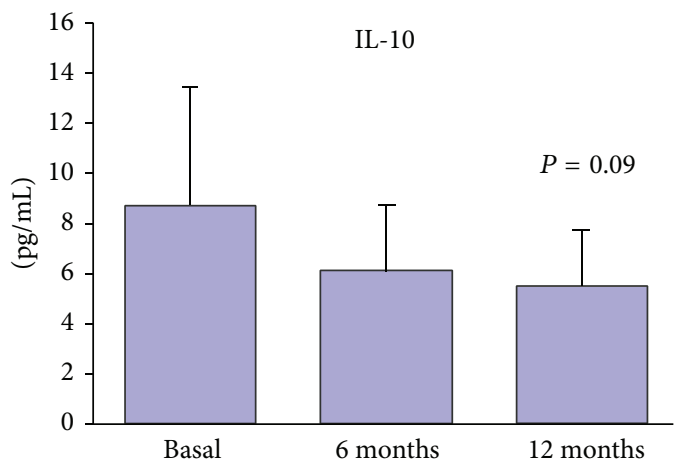

(f)

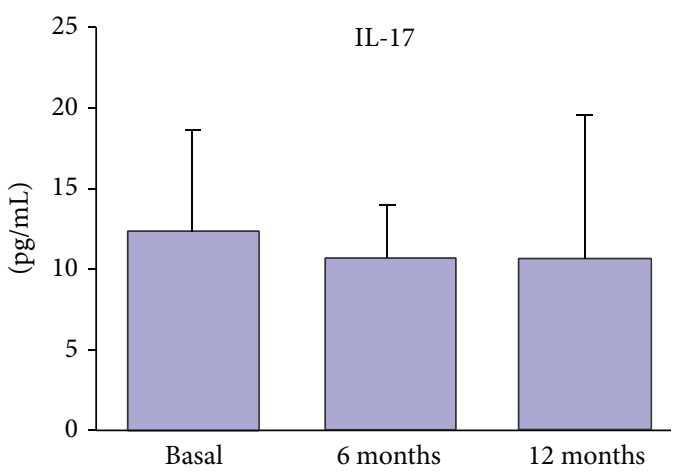

(h)

FIGURE 2: Levels of $\mathrm{Th}_{1}$, some $\mathrm{T}_{\text {reg }}$ and $\mathrm{Th}_{17}$ cytokines in the active group (mean and standard error of patients- $n=30$-at basal time and 6 and 12 months). In control group there were no differences at any time. 


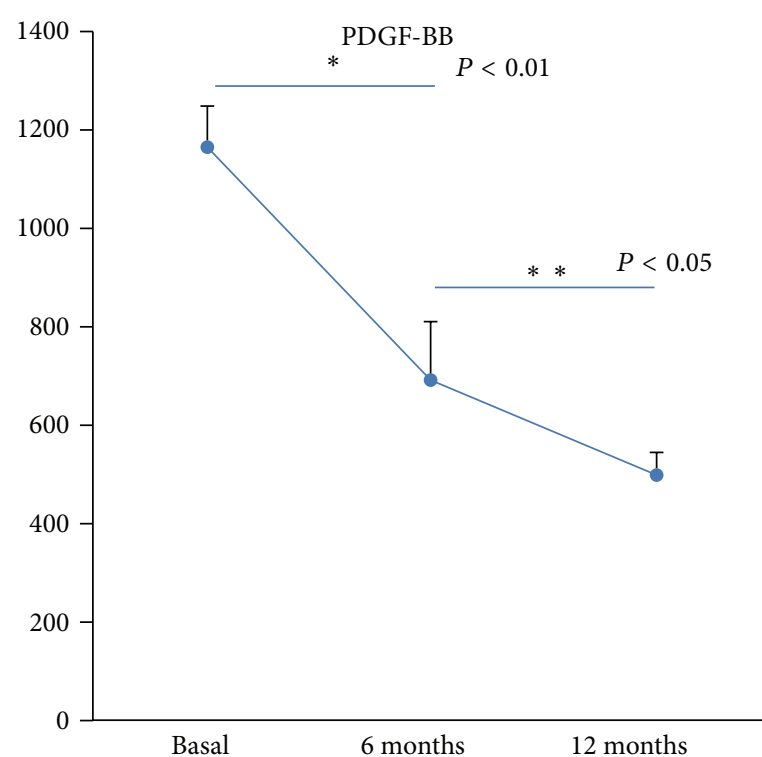

(a)

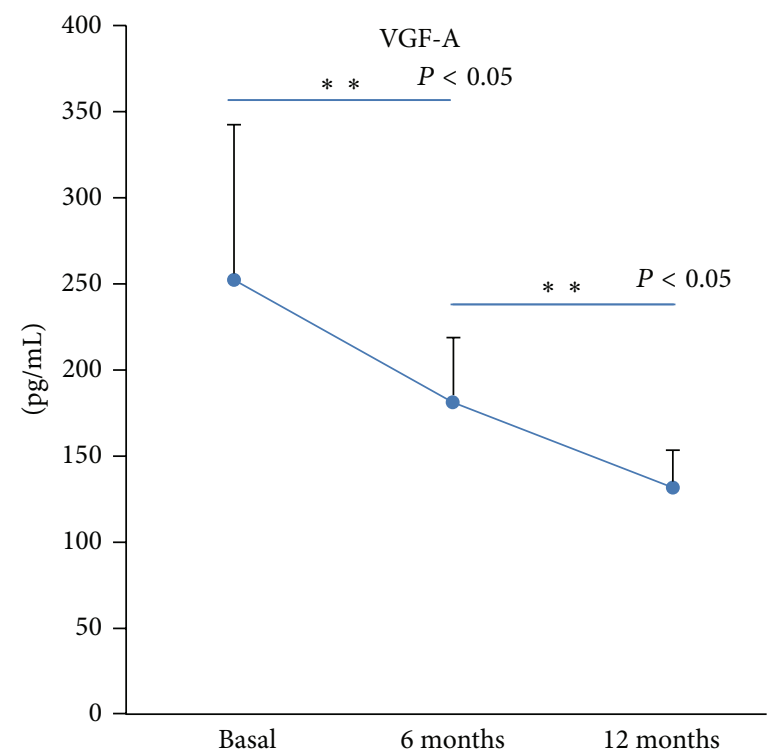

(b)

FIGURE 3: Levels of PDGF-bb and VEGF-A in the active group (mean and standard error of patients $-n=30-$ at basal time and 6 and 12 months). In control group there were no differences at any time.

cytokines did not significantly change throughout the CMP desensitization. However, there are several subtle changes which, although they are not significantly different, have a clear tendency to be. The nonsignificant changes in IL-5 levels were unexpected, although the $P$ value showed a trend $(P=$ 0.06 ). We have highlighted this result as a result that is not statistically significant, but the trend is clear. This result is correlated with the decrease of VEGF and with the decrease of the levels of eotaxin $(P=0.06)$. Similarly, it has been seen with peripheral eosinophils as it has been shown before $[24,25]$. However, we did not find any clear tendency in Eosinophilia in our patients. Eosinophilia, which is a marker of allergic processes, especially with respiratory allergy, could increase in cases of occurrence of respiratory sensitization against mites or could decrease in patients with improvement in their atopic dermatitis. All these results would support a cause/effect about the immune-modulatory changes derived from oral immunotherapy. That is why we decided not to include such data in the present paper. All these results would support a cause/effect about the immune-modulatory changes derived from oral immunotherapy.

In case of other important cytokines, we did not see differences. In some cases, such as IFN- $\gamma$, we firmly think that the assay is not the optimal procedure to detect subtle changes since the detected levels in our samples were extremely low. This should be better informed to avoid spending time and effort in an assay that is better for other molecules.

Downregulation of both VEGF and PDGF [26] after the rapid IgE desensitization, an antigen-specific method that prevents mast cell degranulation and protects patients from food and drug anaphylaxis, [27] has proved as a valuable method to obtain a temporary immunotolerance. This issue along with the additional oral antigen-specific immunotherapy may evidence the a possible mobilization of calcium through into voltage-dependent calcium channels in the desensitization of beta-adrenoceptors in the airway smooth muscle as speculated before [28] and this could be linked to the changes in the levels of PGDF [29]. It could also reflect the result of mast cell degranulation and differential inflammatory cell recruitment, in response to the antigenspecific continuous challenge [27].

Desensitization protocols with drugs have been well described but are considered risky procedures [30] although they may become easier to accomplish when the target cells are found in their refractory period [31] as recently revised [32].

After an accurate diagnosis [33, 34], a rush CMP desensitization protocol is an effective therapeutic intervention for patients with persistent CMP allergy to achieve a clinical tolerance, although immunological tolerance is still unclear [15]. As food allergy probably results from a failure of the correct development of ordinary oral tolerance, the oral route in OIT takes advantage of the cells and immune pathways involved in the induction of oral tolerance. The possible mechanisms of oral food desensitization included increased milk-specific IgG4 with decreased levels of specific IgE followed by decreased activation of mast cells and basophils with their related cytokines. The early downregulation either of IgE or mast cell activating factors could address the success of the oral desensitization therapy, even on those patients with basal high levels of CMP sIgE.

At this time it is unclear if a permanent clinical tolerance could be achieved or it is only transient depending on the maintenance of daily dose [2]. Our data proved that CMP desensitization is a complex process with the potential to induce early immunological changes, not only in the humoral 
response, that is, sIgE and IGg4, but also in mast cell activity markers, that is, angiogenic factors, that may be of use in the immunological outcome of OIT.

Although this is the first description of the PDGF and VEGF angiogenic factors related to food desensitization in human anaphylaxis, more biological markers are needed to characterize the pathogenesis of this disease.

\section{Ethical Approval}

Compilation of data was recorded following European standards of data protection and study was approved by the Clinical Research Ethics Committee of the University Hospital (HUNSC: P.I-35/11).

\section{Conflict of Interests}

The authors declare that there is no conflict of interests regarding the publication of this paper.

\section{Authors' Contributions}

Paloma Poza-Guedes and Yvelise Barrios equally contributed to the paper. P. Poza-Guedes was the main researcher in the fieldwork performing the desensitization in the Paediatric Intensive Care Unit. Y. Barrios was the main researcher in the lab performing all the immunoassays and assessing the results. V. Fuentes, E. Alonso, S. Infante, and L. Zapatero helped in recruiting patients and control group and performing the desensitization in the Allergy Office. I. SánchezMachín collaborated in the original idea, helped in recruiting data, performed all the in vitro study by immunoassays, and discussed the final version of the paper. A. Franco and R. González collaborated in the original idea, helped in recruiting data, performed all the in vitro study by immunoassays, and discussed the final version of the paper. V. Matheu is the principal senior investigator, had the original idea, asked for internal funding, and wrote the final version of the paper. All authors have actively discussed the final version of the paper.

\section{Acknowledgment}

The authors declare that the source of funding has been the internal funding of Unidad de Gestión Alergología-Norte, Hospital del Tórax/Ofra.

\section{References}

[1] N. J. Avery, R. M. King, S. Knight, and J. O. Hourihane, "Assessment of quality of life in children with peanut allergy," Pediatric Allergy and Immunology, vol. 14, no. 5, pp. 378-382, 2003.

[2] J. M. Skripak, E. C. Matsui, K. Mudd, and R. A. Wood, “The natural history of IgE-mediated cow's milk allergy," The Journal of Allergy and Clinical Immunology, vol. 120, no. 5, pp. 1172-1177, 2007.

[3] F. E. R. Simons, "Anaphylaxis," The Journal of Allergy and Clinical Immunology, vol. 125, no. 2, supplement 2, pp. S161-S181, 2010.
[4] A. M. Branum and S. L. Lukacs, "Food allergy among children in the United States," Pediatrics, vol. 124, no. 6, pp. 1549-1555, 2009.

[5] R. V. Hoch and P. Soriano, "Roles of PDGF in animal development," Development, vol. 130, no. 20, pp. 4769-4784, 2003.

[6] M. Uutela, M. Wirzenius, K. Paavonen et al., "PDGF-D induces macrophage recruitment, increased interstitial pressure, and blood vessel maturation during angiogenesis," Blood, vol. 104, no. 10, pp. 3198-3204, 2004.

[7] M. Hoshino, M. Takahashi, and N. Aoike, "Expression of vascular endothelial growth factor, basic fibroblast growth factor, and angiogenin immunoreactivity in asthmatic airways and its relationship to angiogenesis," The Journal of Allergy and Clinical Immunology, vol. 107, no. 2, pp. 295-301, 2001.

[8] R. S. Kerbel, “Tumor angiogenesis," The New England Journal of Medicine, vol. 358, no. 19, pp. 2039-2049, 2008.

[9] S. Zgraggen, A. M. Ochsenbein, and M. Detmar, "An important role of blood and lymphatic vessels in inflammation and allergy," Journal of Allergy, vol. 2013, Article ID 672381, 9 pages, 2013.

[10] V. Bhandari, R. Choo-Wing, S. P. Chapoval et al., "Essential role of nitric oxide in VEGF-induced, asthma-like angiogenic, inflammatory, mucus, and physiologic responses in the lung," Proceedings of the National Academy of Sciences of the United States of America, vol. 103, no. 29, pp. 11021-11026, 2006.

[11] D. Ribatti, I. Puxeddu, E. Crivellato, B. Nico, A. Vacca, and F. Levi-Schaffer, "Angiogenesis in asthma," Clinical and Experimental Allergy, vol. 39, no. 12, pp. 1815-1821, 2009.

[12] S. S. Kristan, M. M. Malovrh, M. Silar et al., "Airway angiogenesis in patients with rhinitis and controlled asthma," Clinical and Experimental Allergy, vol. 39, no. 3, pp. 354-360, 2009.

[13] Y. Zhang, H. Matsuo, and E. Morita, "Increased production of vascular endothelial growth factor in the lesions of atopic dermatitis," Archives of Dermatological Research, vol. 297, no. 9, pp. 425-429, 2006.

[14] G. Jimenez-Andrade, A. Ibarra-Sanchez, D. Gonzalez, M. Lamas, and C. Gonzalez-Espinosa, "Innmunoglobulin E induces VEGF production in mast cells and potentiates their pro-tumorigenic actions through a Fyn kinase-dependent mechanism," Journal of Hematology \& Oncology, vol. 6, article 56, 2013.

[15] P. Poza, R. Glez, Y. Barrios, A. Franco, and V. Matheu, "MIPlalpha, MCP-1, and desensitization in anaphylaxis from cow's milk," The New England Journal of Medicine, vol. 367, no. 3, pp. 282-284, 2012.

[16] "Guidance on food allergy in children," The Lancet, vol. 377, no. 9767, p. 691, 2011.

[17] F. E. R. Simons and K. J. Simons, "Epinephrine (adrenaline) in anaphylaxis," Chemical Immunology and Allergy, vol. 95, pp. 211$222,2010$.

[18] J. Benveniste, P. M. Henson, and C. G. Cochrane, "Leukocytedependent histamine release from rabbit platelets. The role of IgE, basophils, and a platelet-activating factor," The Journal of Experimental Medicine, vol. 136, no. 6, pp. 1356-1377, 1972.

[19] P. Vadas, M. Gold, B. Perelman et al., "Platelet-Activating Factor, PAF acetylhydrolase, and severe anaphylaxis," The New England Journal of Medicine, vol. 358, no. 1, pp. 28-35, 2008.

[20] P. Vadas, B. Perelman, and G. Liss, "Platelet-activating factor, histamine, and tryptase levels in human anaphylaxis," The Journal of Allergy and Clinical Immunology, vol. 131, no. 1, pp. 144-149, 2013. 
[21] P. Vadas and B. Perelman, "Effect of epinephrine on plateletactivating factor-stimulated human vascular smooth muscle cells," The Journal of Allergy and Clinical Immunology, vol. 129, no. 5, pp. 1329-1333, 2012.

[22] I. Puxeddu, A. Alian, A. M. Piliponsky, D. Ribatti, A. Panet, and F. Levi-Schaffer, "Human peripheral blood eosinophils induce angiogenesis," The International Journal of Biochemistry \& Cell Biology, vol. 37, no. 3, pp. 628-636, 2005.

[23] M. Hoshino, Y. Nakamura, and Q. A. Hamid, "Gene expression of vascular endothelial growth factor and its receptors and angiogenesis in bronchial asthma," The Journal of Allergy and Clinical Immunology, vol. 107, no. 6, pp. 1034-1038, 2001.

[24] B. Maitre, S. Boussat, D. Jean et al., "Vascular endothelial growth factor synthesis in the acute phase of experimental and clinical lung injury," European Respiratory Journal, vol. 18, no. 1, pp. 100106, 2001.

[25] Y. Nishigaki, S. Fujiuchi, Y. Yamazaki et al., "Increased vascular endothelial growth factor in acute eosinophilic pneumonia," European Respiratory Journal, vol. 21, no. 5, pp. 774-778, 2003.

[26] P. A. Frischmeyer-Guerrerio, A. L. Guerrerio, K. L. Chichester et al., "Dendritic cell and T cell responses in children with food allergy," Clinical and Experimental Allergy, vol. 41, no. 1, pp. 6171, 2011.

[27] V. Matias, L. San Feliciano, J. E. Fernandez et al., "Host and environmental factors influencing respiratory secretion of prowheezing biomarkers in preterm children," Pediatric Allergy and Immunology, vol. 23, no. 5, pp. 441-447, 2012.

[28] T. Ikenouchi, H. Kume, T. Oguma et al., "Role of $\mathrm{Ca}^{2+}$ mobilization in desensitization of $\beta$-adrenoceptors by platelet-derived growth factor in airway smooth muscle," European Journal of Pharmacology, vol. 591, no. 1-3, pp. 259-265, 2008.

[29] N. Suganuma, S. Ito, H. Aso et al., "STIM1 regulates plateletderived growth factor-induced migration and $\mathrm{Ca}^{2+}$ influx in human airway smooth muscle cells," PLoS ONE, vol. 7, no. 9, Article ID e45056, 2012.

[30] V. Matheu, E. Perez, M. Hernández et al., "Insulin allergy and resistance successfully treated by desensitisation with Aspart insulin," Clinical and Molecular Allergy, vol. 3, article 16, 2005.

[31] A. Prieto-García, D. Zheng, R. Adachi et al., "Mast cell restricted mouse and human tryptase-heparin complexes hinder thrombin-induced coagulation of plasma and the generation of fibrin by proteolytically destroying fibrinogen," The Journal of Biological Chemistry, vol. 287, no. 11, pp. 7834-7844, 2012.

[32] A. Liu, L. Fanning, H. Chong et al., "Desensitization regimens for drug allergy: state of the art in the 21st century," Clinical and Experimental Allergy, vol. 41, no. 12, pp. 1679-1689, 2011.

[33] M. R. Murali, M. C. Castells, J. Y. Song, D. M. Dudzinski, and R. P. Hasserjian, "Case 9-2011: a 37-year-old man with flushing and hypotension," The New England Journal of Medicine, vol. 364, no. 12, pp. 1155-1165, 2011.

[34] J. J. Ross, A. Saavedra, R. A. Vleugels, A. Liu, and M. C. Castells, "Interactive medical case. A rash hypothesis," The New England Journal of Medicine, vol. 362, no. 24, p. e69, 2010. 


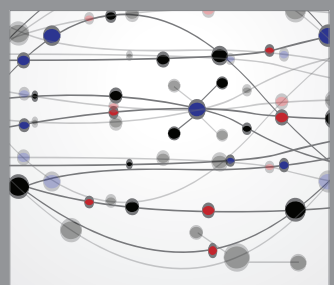

The Scientific World Journal
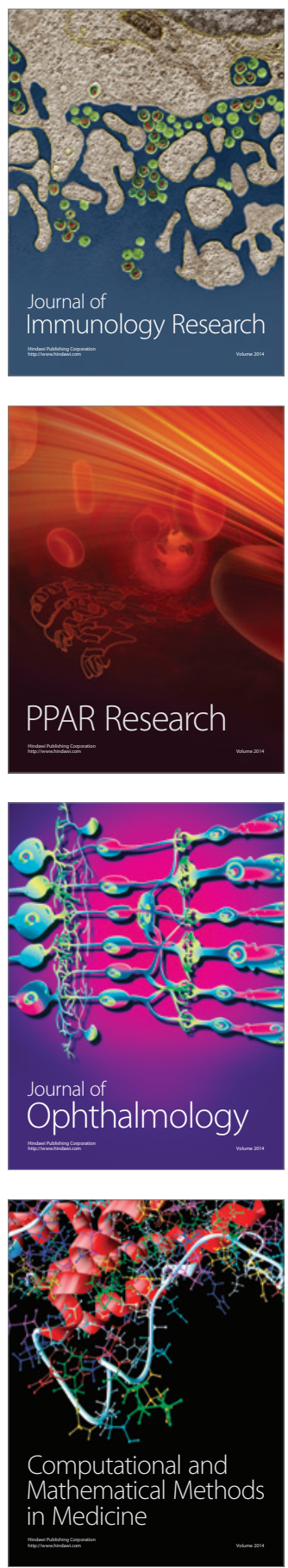

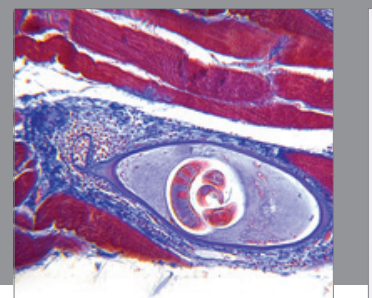

Gastroenterology

Research and Practice
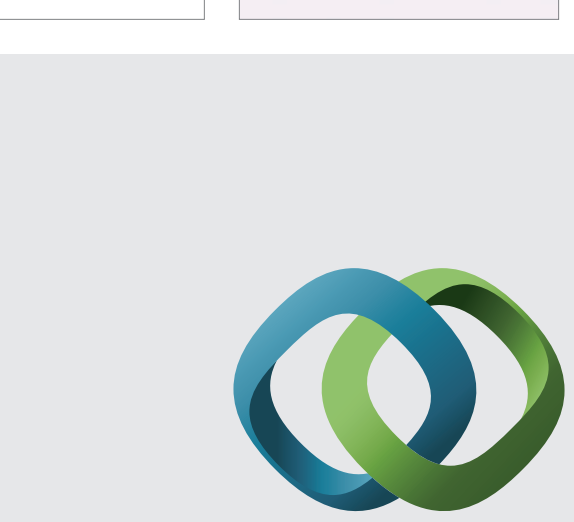

\section{Hindawi}

Submit your manuscripts at

http://www.hindawi.com
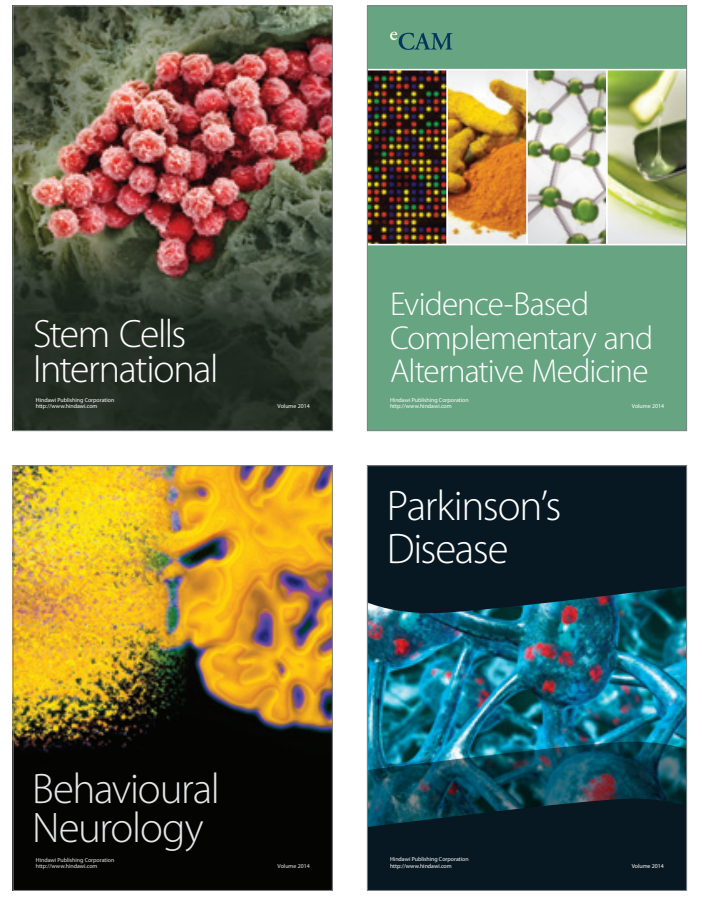
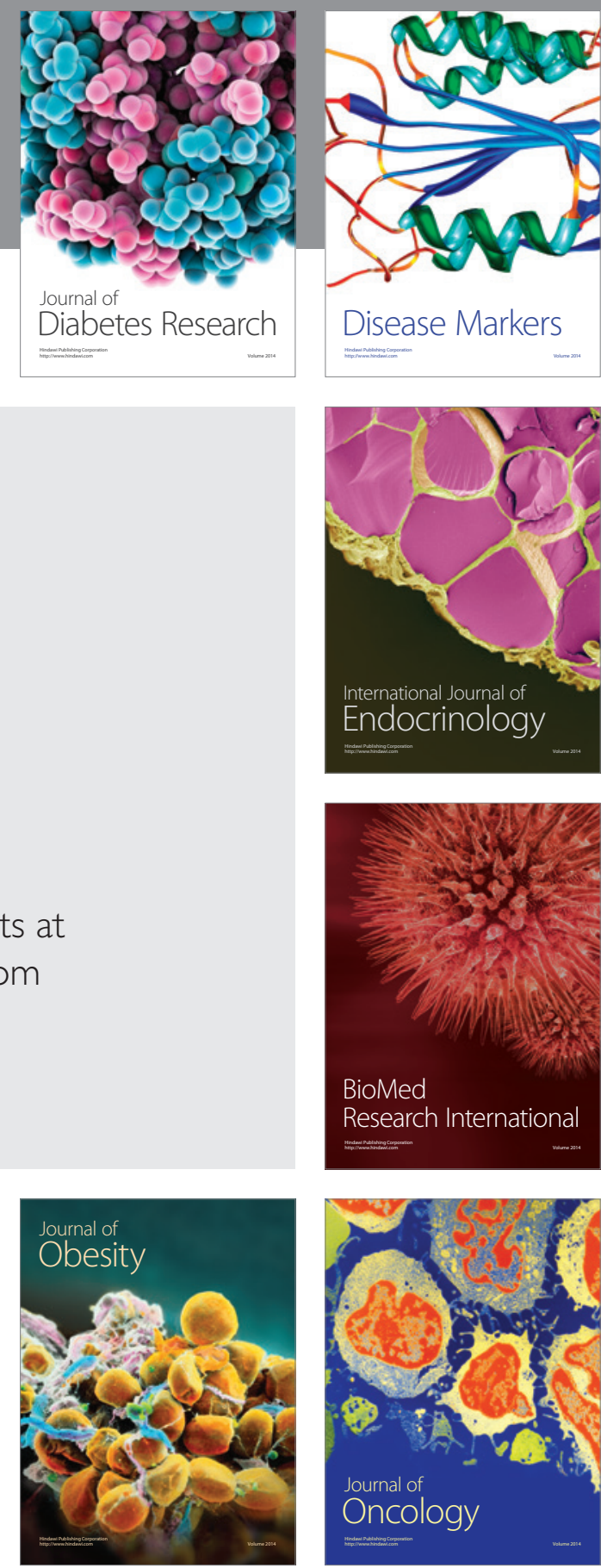

Disease Markers
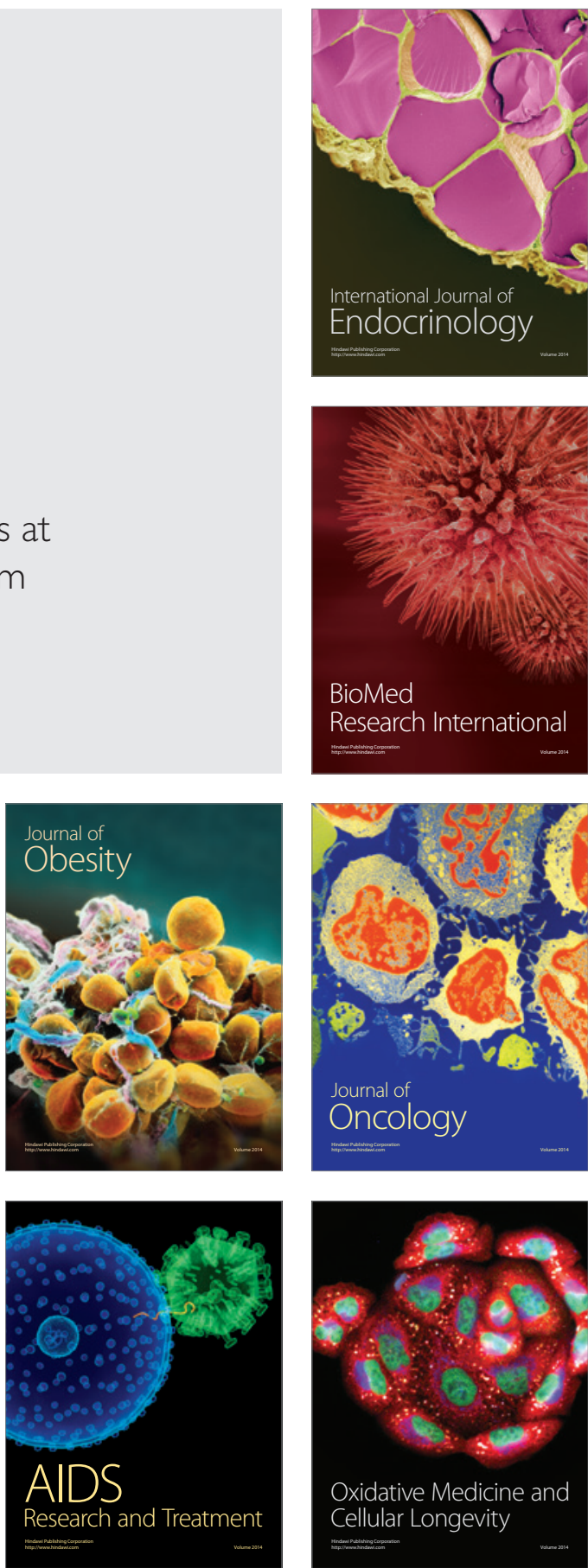